\title{
PERSEPSI SISWA TENTANG KEMAMPUAN GURU DALAM MENGELOLA KELAS DAN MOTIVASI BELAJAR SISWA
}

\author{
Lusi Gustiana \\ SMP Air Molek Indragiri Hulu Provinsi Riau \\ email: lusigustiana@gmail.com
}

\begin{abstract}
Teachers are required to be able to manage the class with good way. If the class has good managed, it is expected that students' learning motivation will be increased. The purpose of this study are to describes: 1) students' perceptions of the teacher's ability in class management at MTs Nurul Falah Airmolek, Subdistrict of Pasir Penyu, Indragiri Hulu Regency ?; 2) learning motivation of eighth grade students at MTs Nurul Falah Airmolek, Subdistrict of Pasir Penyu, Indragiri Hulu Regency ?; and 3) the relationship between students' perceptions of the teacher's ability in class management and learning motivation of eighth grade students of MTs Nurul Falah Airmolek, Subdistrict of Pasir Penyu, Indragiri Hulu Regency? This research was a correlation study, which connected the students' perceptions of the teacher's ability in class management and learning motivation of eighth grade students at MTs Nurul Falah Airmolek. The population in this study were all students of class VIII MTs Nurul Falah, there were 95 as the sample. Meanwhile, the population is not more than 100 people. Thus, the instrument used to collect data in this study is a questionnaire. The questionnaire has been tried out first to find the validity and reliability test. To determine the relationship between students' perceptions of the teacher's ability in class management and student learning motivation, the data was analyzed through contingency coefficient correlation techniques because the data produced are not normally distributed and not linear. The findings of this study showed that: 1) students' perceptions of the teacher's ability in class management at MTs Nurul Falah Airmolek, Pasir Penyu Subdistrict, Indragiri Hulu District, are mostly classified as medium; 2) learning motivation of eighth grade students at MTs Nurul Falah Airmolek, Pasir Penyu Subdistrict, Indragiri Hulu Regency, is mostly classified as medium; and 3) there is a relationship between students' perceptions of the teacher's ability to manage classes and learning motivation of eighth grade students at MTs Nurul Falah Airmolek, Pasir Penyu District, Indragiri Hulu Regency.
\end{abstract}

Keyword: Perception, Classroom Management Skills, Learning Motivation 


\section{PENDAHULUAN}

Dalam keseluruhan proses pendidikan di sekolah, kegiatan belajar merupakan kegiatan paling pokok. Keberhasilan belajar siswa ditentukan oleh beberapa faktor, antara lain guru serta kondisi dan suasana di dalam kelas. Oleh karena itu, guru yang berfungsi sebagai pengelola kelas dituntut untuk mampu menciptakan kondisi belajar mengajar yang memberikan rangsangan kepada siswa sehingga siswa mau belajar.

Proses belajar mengajar merupakan suatu proses yang mengandung serangkaian perbuatan guru dan siswa atas dasar hubungan timbal balik yang berlangsung dalam situasi edukatif untuk mencapai tujuan tertentu. Interaksi atau hubungan timbal balik antara guru dan siswa itu merupakan syarat utama bagi berlangsungnya proses belajar mengajar. Dalam proses belajar mengajar tersirat adanya suatu kegiatan yang tak terpisahkan antara siswa yang belajar dan guru yang mengajar. Antara kedua kegiatan ini terjalin interaksi yang saling menunjang.

Harapan yang tidak pernah sirna dan selalu guru tuntut adalah bagaimana bahan pelajaran yang disampaikan guru dapat dikuasai oleh anak didik secara tuntas, ini merupakan masalah yang cukup sulit yang dirasakan guru. Kesulitan itu dikarenakan anak didik bukan hanya sebagai individu dengan segala keunikannya, tatapi mereka juga sebagai makhluk sosial dengan latar belakang yang berlainan.

Masalah pokok yang dihadapi guru, baik yang pemula maupun yang sudah berpengalaman adalah masalah pengelolaan kelas, ini merupakan aspek yang sering didiskusikan oleh para pengajar. Pengelolaan kelas merupakan masalah tingkah laku yang kompleks, dan guru menggunakannya untuk menciptakan dan mempertahankan kondisi kelas sedemikian rupa, sehingga anak didik dapat mencapai tujuan pengajaran secara efisien dan memungkinkan mereka dapat belajar. Dengan demikian pengelolaan kelas yang efektif adalah syarat bagi pengajaran yang efektif.

Menurut Sudirman dalam Syaiful Bahri Djamarah (2005, p. 172), pengelolaan kelas merupakan upaya dalam mendayagunakan potensi kelas. Karena itu, kelas mempunyai peranan dan fungsi tertentu dalam menunjang keberhasilan proses interaksi edukatif. Maka agar memberikan dorongan dan rangsangan terhadap anak didik untuk belajar, kelas harus dikelola sebaik-baiknya oleh guru.

Pengelolaan kelas yang efektif punya dua tujuan yakni membantu siswa menghabiskan lebih banyak waktu untuk belajar dan mengurangi waktu aktivitas yang tidak diorientasikan pada tujuan, serta mencegah siswa mengalami problem akademik dan emosional (Santrock, 2007, p. 558). 
Dalam perannya sebagai pengelola kelas (learning manager), guru hendaknya mampu mengelola kelas sebagai lingkungan belajar, sebab hal itu merupakan aspek dari lingkungan sekolah yang perlu diorganisasi. Lingkungan ini diatur dan diawasi agar kegiatan-kegiatan belajar terarah kepada tujuan-tujuan pendidikan. Pengawasan terhadap lingkungan belajar itu turut menentukan sejauh mana lingkungan tersebut menjadi lingkungan belajar yang baik. Lingkungan yang baik ialah yang bersifat menantang dan merangsang siswa untuk belajar atau memotivasi siswa untuk belajar, memberikan rasa aman dan kepuasan dalam mencapai tujuan.

Secara historis, kelas yang dikelola secara efektif dideskripsikan sebagai semacam "mesin berpelumas bagus", tetapi metafora yang lebih tepat untuk kelas yang efektif sekarang ini adalah "sarang atau panggung aktivitas", ini bukan berarti bahwa kelas harus ramai. Sebaliknya, siswa harus belajar secara aktif dan sibuk mengerjakan tugas yang membuat mereka termotivasi, bukan sekedar duduk diam mendengarkan (Santrock, 2007, p. 557).

Menurut Santrock (2007, p. 559) kelas yang dikelola dengan baik akan meningkatkan pembelajaran yang berarti, membantu mencegah berkembangnya problem emosional dan akademik, membuat siswa sibuk dengan tugas yang menantang, memberikan aktivitas di mana siswa menjadi terserap ke dalamnya dan termotivasi untuk belajar serta memahami aturan dan regulasi yang harus dipatuhi. Dalam kelas seperti itu, siswa kecil kemungkinannya mengalami masalah emosional dan akademik. Sebaliknya, dalam kelas yang dikelola dengan buruk, problem emosional dan akademik akan lebih mudah muncul. Siswa yang tidak termotivasi secara akademik akan menjadi makin tidak termotivasi.

Dengan demikian, guru dituntut untuk mampu mengelola kelas dengan baik dalam proses belajar mengajar. Apabila kelas dikelola dengan baik, diharapkan motivasi belajar siswa akan meningkat.

Motivasi berasal dari kata motif (motive), dalam bahasa Inggrisnya motion, yang berarti gerakan atau sesuatu yang bergerak (Fauzi, 1999, p. 59). Menurut Nasution (2000:73) motivasi juga bisa diartikan sebagai segala daya yang mendorong seseorang untuk melakukan sesuatu. Motivasi merupakan aspek penting dari pengajaran dan pembelajaran. Siswa yang tidak punya motivasi tidak akan berusaha keras untuk belajar. Motivasi adalah proses yang memberi semangat, arah dan kegigihan perilaku yang penuh energi, terarah dan bertahan lama.

Menurut Sardiman A. M (2007) ada beberapa ciri-ciri siswa yang memiliki motivasi belajar, di antaranya tekun menghadapi tugas, ulet menghadapi kesulitan, menunjukkan minat terhadap bermacam-macam masalah, lebih senang bekerja mandiri, tidak suka terhadap tugastugas yang tidak meningkatkan kreatifitas, dapat mempertahankan pendapatnya, tidak mudah melepaskan hal yang diyakininya itu dan senang mencari dan memecahkan masalah soal-soal. 
Madrasah Tsanawiyah (MTs) Nurul Falah adalah salah satu MTs yang ada di Airmolek Kecamatan Pasir Penyu Kabupaten Indragiri Hulu. MTs ini berdiri sejak tahun 1937. Apabila dihubungkan dengan uraian di atas, maka guru-guru di MTs Nurul Falah pun dituntut untuk mampu mengelola kelas dengan baik, sehingga diharapkan dapat meningkatkan motivasi belajar siswa.

Namun berdasarkan pengamatan penulis, ditemukan gejala-gejala sebagai berikut: 1) ada sebagian ruang kelas yang belum ditata atau diatur; 2) ada kelas yang anak didiknya belum diatur tempat duduknya; 3) ada sebagian siswa yang tidak giat atau tidak bersemangat dalam belajar dan 4) ada sebagian yang tidak bisa fokus dalam belajar.

Adapun rumusan masalah dalam penelitian ini antara lain: 1) bagaimana persepsi siswa tentang kemampuan guru dalam mengelola kelas di MTs Nurul Falah Airmolek Kecamatan Pasir Penyu Kabupaten Indragiri Hulu?; 2) bagaimana motivasi belajar siswa kelas VIII di MTs Nurul Falah Airmolek Kecamatan Pasir Penyu Kabupaten Indragiri Hulu?; dan 3) apakah ada hubungan persepsi siswa tentang kemampuan guru mengelola kelas dan motivasi belajar siswa kelas VIII MTs Nurul Falah Airmolek Kecamatan Pasir Penyu Kabupaten Indragiri Hulu?.

\section{METODOLOGI}

Penelitian ini merupakan penelitian korelasi, yang menghubungkan antara persepsi siswa tentang kemampuan guru dalam mengelola kelas dan motivasi belajar siswa kelas VIII di MTs Nurul Falah Airmolek. Dalam penelitian ini populasi yang diambil adalah seluruh siswa kelas VIII MTs Nurul Falah yang berjumlah 95 orang. Mengingat populasinya tidak lebih dari 100 orang, sehingga penelitiannya merupakan penelitian populasi atau total sampling. Instrumen yang digunakan untuk mengumpulkan data dalam penelitian ini berbentuk kuesioner (angket), yaitu untuk mendapatkan data persepsi siswa tentang kemampuan guru dalam mengelola kelas dan motivasi belajar siswa kelas VIII di MTs Nurul Falah Airmolek.. Jenis angket yang penulis gunakan adalah angket tertutup dimana setiap item pertanyaan telah disediakan empat (4) buah alternatif jawaban, yaitu SS, S, TS, dan STS. Angket tersebut telah melewati uji validitas dan reliabilitas. Untuk mengetahui hubungan persepsi siswa tentang kemampuan guru dalam mengelola kelas dan motivasi belajar siswa, maka data akan dianalisis melalui teknik korelasi 


\section{TEMUAN}

\section{Hasil Penelitian}

Data yang telah terkumpul dianalisis untuk menjawab rumusan masalah yang telah diajukan yakni apakah ada hubungan yang signifikan antara persepsi siswa tentang kemampuan guru dalam mengelola kelas dan motivasi belajar siswa kelas VIII di MTs Nurul Falah Airmolek. Untuk mengolah data di atas penulis menggunakan bantuan komputerisasi melalui program SPSS 16.0 For Windows.

Setelah data persepsi siswa tentang kemampuan guru dalam mengelola kelas dianalisis, deskripsinya sebagai berikut:

Tabel 1. Gambaran Rerata Empirik dan Hipotetik Variabel Persepsi Siswa Tentang Kemampuan Guru dalam Mengelola Kelas

\begin{tabular}{lrrrrrr}
\hline & N & Range & Minimum & Maximum & Mean & Std. Deviation \\
\hline Variabel X & 95 & 39.00 & 43.00 & 82.00 & 62.7158 & 7.76608 \\
\hline Valid N (listwise) & 95 & & & & & \\
\hline
\end{tabular}

Berdasarkan hasil uraian di atas diketahui bahwa variabel persepsi siswa tentang kemampuan guru dalam mengelola kelas di MTs Nurul Falah Airmolek, Skor terendah 43 dan skor tertinggi 82, Mean = 62.71 dibulatkan menjadi 63 dan Standard Deviasinya 7.76 dibulatkan menjadi 8 .

Deskripsi mengenai ketercapaian responden pada variable persepsi siswa tentang kemampuan guru dalam mengelola kelas dipaparkan pada tabel berikut ini:

Tabel 2. Distribusi Frekuensi Relative Persepsi Siswa Tentang Kemampuan Guru dalam Mengelola Kelas Datavarian 1 (X)

\begin{tabular}{cccc}
\hline Kategori & Nilai & Frekuensi & Persentase (\%) \\
\hline Positif & $72-82$ & 12 & $12,63 \%$ \\
Sedang & $55-71$ & 68 & $71,58 \%$ \\
Negatif & $43-54$ & 15 & $15,79 \%$ \\
\hline Jumlah & & $\mathbf{9 5}$ orang & $\mathbf{1 0 0 \%}$ \\
\hline
\end{tabular}

Dari tabel di atas dapat dilihat gambaran tentang persepsi siswa tentang kemampuan guru dalam mengelola kelas di MTs Nurul Falah Airmolek yang secara umum tergolong sedang, yakni sebanyak 68 orang atau sebesar 71.58\%, pada kategori positif sebanyak 12 orang atau sebesar $12.63 \%$, dan pada kategori negatif sebanyak 15 orang atau sebesar $15.79 \%$. 
Selanjutnya data motivasi belajar siswa dideskripsikan pada tabel berikut ini:

Tabel 3. Gambaran Rerata Empirik dan Hipotetik Variabel Motivasi Belajar Siswa (Y)

\begin{tabular}{lrrrrrr}
\hline & N & Range & Minimum & Maximum & Mean & Std. Deviation \\
\hline VAR00001 & 95 & 38.00 & 33.00 & 71.00 & 56.2000 & 7.78925 \\
\hline Valid N (listwise) & 95 & & & & & \\
\hline
\end{tabular}

Berdasarkan hasil uraian di atas diketahui bahwa variabel motivasi belajar siswa kelas VIII di MTs Nurul Falah Airmolek, Skor terendah 33 dan skor tertinggi 71, Mean $=56.20$ dibulatkan menjadi 56 dan Standard Deviasinya 7.79 dibulatkan menjadi 8.

Deskripsi mengenai ketercapaian responden pada variabel motivasi belajar siswa dipaparkan pada tabel berikut ini:

Tabel 4. Distribusi Frekuensi Relative tentang Motivasi Belajar Siswa Datavarian 1 (Y)

\begin{tabular}{cccc}
\hline Kategori & Nilai & Frekuensi & Persentase (\%) \\
\hline Tinggi & $65-71$ & 14 & $14,74 \%$ \\
Sedang & $48-64$ & 66 & $69,47 \%$ \\
Rendah & $33-47$ & 15 & $15,79 \%$ \\
& & & $\mathbf{1 0 0} \%$ \\
\hline
\end{tabular}

Dari tabel di atas dapat dilihat gambaran tentang motivasi belajar siswa kelas VIII di MTs Nurul Falah Airmolek yang secara umum tergolong sedang, yakni sebanyak 66 orang atau sebesar $69.47 \%$, pada kategori tinggi sebanyak 14 orang atau sebesar $14.74 \%$, dan pada kategori rendah sebanyak 15 orang atau sebesar $15.79 \%$.

Selanjutnya untuk mencari hubungan persepsi siswa tentang kemampuan guru dalam mengelola kelas dan motivasi belajar siswa digunakan rumus korelasi koefisien kontingensi dikarenakan data yang diperoleh tidak berdistribusi normal dan tidak linear.

Table 5. Tabel Silang Data Persepsi Siswa Tentang Kemampuan Guru Dalam Mengelola Kelas dan Motivasi Belajar Siswa

\begin{tabular}{|c|c|c|c|c|c|c|}
\hline & & & \multicolumn{3}{|c|}{ VariabelY } & \multirow[b]{2}{*}{ Total } \\
\hline & & & Rendah & Sedang & Tinggi & \\
\hline \multirow[t]{6}{*}{ VariabelX } & Negatif & Count & 6 & 6 & 3 & 15 \\
\hline & & Expected Count & 2.4 & 10.4 & 2.2 & 15.0 \\
\hline & Sedang & Count & 7 & 54 & 7 & 68 \\
\hline & & Expected Count & 10.7 & 47.2 & 10.0 & 68.0 \\
\hline & Positif & Count & 2 & 6 & 4 & 12 \\
\hline & & Expected Count & 1.9 & 8.3 & 1.8 & 12.0 \\
\hline \multirow[t]{2}{*}{ Total } & & Count & 15 & 66 & 14 & 95 \\
\hline & & Expected Count & 15.0 & 66.0 & 14.0 & 95.0 \\
\hline
\end{tabular}


Tabel 6. Koefisien Kontingensi

\begin{tabular}{lccc}
\hline & & Value & Approx. Sig. \\
\hline Nominal by Nominal & Contingency Coefficient & .363 & .006 \\
\hline N of Valid Cases & & 95 & \\
\hline
\end{tabular}

Dari hasil output program SPSS diketahui bahwa koefisien korelasi antara variabel X dan Y (persepsi siswa tentang kemampuan guru dalam mengelola kelas dan motivasi belajar siswa) adalah 0,363 dengan tingkat probabilitas 0,006. Koefisien korelasi sebesar 0,363 mengandung arti adanya hubungan antara kedua variabel. Selain itu karena probabilitas yang diperoleh 0,006 lebih kecil dari 0,05 maka Ho yang berbunyi tidak ada hubungan yang signifikan antara persepsi siswa tentang kemampuan guru dalam mengelola kelas dan motivasi belajar siswa kelas VIII di MTs Nurul Falah Airmolek ditolak. Dengan sendirinya Ha yang berbunyi ada hubungan yang signifikan antara persepsi siswa tentang kemampuan guru dalam mengelola kelas dan motivasi belajar siswa kelas VIII di MTs Nurul Falah Airmolek diterima. Dengan kata lain semakin positif persepsi siswa tentang kemampuan guru dalam mengelola kelas maka akan semakin tinggi motivasi belajar siswa.

\section{Pembahasan}

Pengelolaan kelas adalah upaya dalam mendayagunakan potensi kelas. Karena itu, kelas mempunyai peranan dan fungsi tertentu dalam menunjang keberhasilan proses interaksi edukatif. Maka agar memberikan dorongan dan rangsangan (motivasi) terhadap anak didik untuk belajar, kelas harus dikelola sebaik-baiknya oleh guru.

Guru yang mampu mengelola kelas dengan baik harus bisa menciptakan iklim sekolah yang kondusif. Iklim sekolah adalah situasi atau suasana yang muncul akibat hubungan antara kepala sekolah dengan guru, guru dengan guru, guru dengan peserta didik, dan hubungan antar peserta didik, yang mempengaruhi sikap, kepercayaan, nilai, motivasi, dan prestasi orang-orang yang terlibat dalam sekolah.

Sejumlah pemikir dan praktisi dunia pendidikan seperti Hanushek, dalam Desmita (2010:302) menyarankan kepada pihak sekolah agar mampu menciptakan iklim sekolah yang sehat dan menyenangkan. Iklim sekolah yang sehat ini, di samping dibutuhkan untuk membangkitkan motivasi belajar siswa, juga diperlukan untuk mengantisipasi timbulnya perasaan tidak nyaman dan stress dalam diri siswa, yang pada gilirannya akan mempengaruhi prestasi belajar mereka. 
Motivasi adalah aspek penting dari pengajaran dan pembelajaran. Siswa yang tidak punya motivasi tidak akan berusaha keras untuk belajar. Siswa yang bermotivasi tinggi senang ke sekolah dan menyerap proses belajar (Santrock, 2007:559).

Motivasi merupakan suatu keadaan internal ataupun eksternal yang menimbulkan, mengarahkan dan memperkuat perilaku. Dalam pendidikan di sekolah, motivasi sangat erat hubungannya dengan perilaku anak didik pada saat proses belajar dimulai (entering behavior). Bila pendidik (guru) membangkitkan motivasi anak didik, mereka akan memperkuat respon yang telah dipelajari. Respon muncul setelah ada perangsang, sedangkan motif muncul sebelum ada perangsang. Oleh karena itu, dalam entering behavior hendaknya hati-hati melakukan tindakan untuk membangkitkan atau memperkuat motivasi belajar, agar guru dapat membantu anak didik mengembangkan motif belajar ekstrinsik menjadi intrinsik (Ali, 2007:141).

Tindakan-tindakan yang dilakukan oleh guru tersebut di dalam kelas akan memunculkan persepsi siswa tentang kemampuan guru dalam mengelola kelas yang nantinya dapat mempengaruhi motivasi belajar siswa. Hal ini dikarenakan persepsi terbagi atas dua jenis menurut Syafefi (2003:11-12), yaitu :

1) Persepsi positif, adalah manifestasinya berupa rasa senang sehingga dalam memberikan respon/reaksi selanjutnya akan menampakkan kecenderungan untuk berbuat.

2) Persepsi negatif, adalah manifestasinya berupa rasa tidak senang akan menampakkan kecenderungan reaksi untuk menghindari, menjauhi dan bisa menimbulkan antisipasi atau cuek.

Persepsi siswa tentang kemampuan guru dalam mengelola kelas memiliki hubungan dengan motivasi belajar siswa. Semakin baik persepsi siswa tentang kemampuan guru dalam mengelola kelas, maka motivasi belajar siswa akan semakin meningkat.

Hasil uji hipotesis membuktikan bahwa terdapat hubungan antara persepsi siswa mengenai kemampuan guru dalam mengelola kelas dengan motivasi belajar siswa. Temuan penelitian ini mendukung hasil-hasil peneliti terdahulu. Maulidah (2017) dalam penelitiannya mengungkapkan bahwa terdapat hubungan antara kemampuan guru dalam mengelola kelas dan motivasi belajar siswa. Hasil yang sama diungkapkan Puspita(2017), bahwa terdapat hubungan yang signifikan antara kedua variable tersebut. Astrini, Hasyim, \& Yanzi. (2015), mengkaji variable tersebut secara spesifik mengenai kemampuan guru dalam mengelola kelas dalam kelompok diskusi, juga ditemukan korelasi yang signifikan antara keduanya. Zulqadry (2015), melakukan penelitian di salah satu Sekolah Menengah Atas di Kab. Janeponto Sulawesi Selatan, ditemukan hasil terdapat pengaruh keterampilan guru dalam mengelola kelas terhadap motivasi belajar siswa. 
Mengingat pentingnya keterampilan guru dalam mengelola kelas, oleh sebab itu kepada guru disarankan untuk mampu menciptakan kondisi belajar mengajar yang dapat memotivasi siswa untuk mau belajar sehingga dapat menumbuhkan persepsi positif siswa terhadap kemampuan guru dalam mengelola kelas. Kepada kepala sekolah juga disarankan untuk memberikan pelatihan-pelatihan atau diklat kepada guru tentang pengelolaan kelas, agar guru dapat meningkatkan kemampuannya dalam pengelolaan kelas.

\section{PENUTUP}

Berdasarkan penyajian data dan analisis data tentang hubungan persepsi siswa tentang kemampuan guru dalam mengelola kelas dan motivasi belajar siswa kelas VIII di MTs Nurul Falah Airmolek, maka dapat ditarik kesimpulan bahwa:

1. Persepsi siswa tentang kemampuan guru dalam mengelola kelas di MTs Nurul Falah Airmolek Kecamatan Pasir Penyu Kabupaten Indragiri Hulu sebagian besar tergolong sedang yakni sebesar $71,58 \%$.

2. Motivasi belajar siswa kelas VIII di MTs Nurul Falah Airmolek Kecamatan Pasir Penyu Kabupaten Indragiri Hulu sebagian besar tergolong sedang yakni sebesar 69,47\%.

3. Ada hubungan persepsi siswa tentang kemampuan guru dalam mengelola kelas dan motivasi belajar siswa kelas VIII di MTs Nurul Falah Airmolek Kecamatan Pasir Penyu Kabupaten Indragiri Hulu. Berdasarkan analisis statistik menghasilkan koefisien korelasi sebesar 0,326. Skor ini lebih besar dari tabel $\mathrm{r}$ product moment baik pada tarap signifikan $5 \%(0,205)$ maupun $1 \%(0,267)$. Atau dengan cara lain dapat ditulis $(0,205<0,326>$ 0,267 ). Ini berarti semakin positif persepsi siswa tentang kemampuan guru dalam mengelola kelas, maka semakin tinggi pula motivasi belajar siswa.

\section{REFERENSI}

Ali, Mohammad. (2007). Ilmu dan Aplikasi Pendidikan. PT Imperial Bhakti Utama,

Astrini, Lintang Ajeng., Hasyim, Adelina., \& Yanzi, Hermi. (2015). Hubungan Kemampuan Guru Mengelola Kelas Dalam Diskusi Kelompok Dengan Motivasi Belajar Siswa. Jurnal Kultur Demokrasi, 3 (2): 1-12.

Desmita. (2010). Psikologi Perkembangan Peserta Didik. Bandung: PT Remaja Rosdakarya.

Djamarah, Syaiful Bahri. (2005). Guru dan Anak Didik Dalam Interaksi Edukatif. Jakarta: PT Rineka Cipta. 
Fauzi, Ahmad. (1999). Psikologi Umum untuk IAIN, STAIN, PTAIS Fakultas Tarbiyah Komponen MKDK. Pustaka setia.

Maulidah, Idah. (2017). Hubungan Kemampuan Guru Mengelola Kelas dengan Motivasi Belajar Siswa di SMK Citra Nusantara Panongan Kabupaten Tangerang. Skripsi tidak diterbitkan. Jakarta: UIN Syarif Hidayatullah.

Nasution, S. (2000). Didaktik Asas-Asas Mengajar. Jakarta: Bumi Aksara.

Purwanto, M. Ngalim. (1991). Psikologi Pendidikan. Bandung: PT Remaja Rosdakarya.

Puspita, Dewi Ria. (2017). Hubungan Keterampilan Guru Mengelola Kelas dengan Motivasi Belajar Siswa di Madrasah Ibtidaiyah Hijriyah II Palembang. Skripsi tidak diterbitkan. Palembang: UIN Raden Fatah.

Santrock, John W. (2007). Psikologi Pendidikan. Jakarta: Kencana.

Sardiman. AM. 2007. Interaksi dan Motivasi Belajar. Jakarta: PT Rajawali.

Syafefi. (2003). Persepsi Terhadap Visi Pendidikan Islam ke Depan di Kalangan Masyarakat Pekanbaru. Jakarta: PT Rosda Karya.

Zulqadry. (2015). Pengaruh Pengelolaan Kelas terhadap Motivasi Belajar Siswa Kelas XI IPS 1 di SMA Negeri 2 Binamu Kabupaten Jeneponto. Jurnal Sosialisasi, 2 (2): 116-119. 